\title{
Lazer como mecanismo de apropriação democrática dos espaços públicos: um estudo sobre as práticas de lazer na Estação das Docas em Belém (Pará, Brasil)
}

\section{Leisure as a mechanism to democratic reinforce of the public spaces: a study of leisure activities at Estação das Docas (Docks), Belém (Pará, Brazil)}

\author{
Pablo Vitor Viana Pereira (PEREIRA, P. V. V.) ${ }^{*} \mathrm{e}$ \\ Lucília da Silva Matos (MATOS, L. S.)
}

\begin{abstract}
RESUMO - Na cidade de Belém (Pará, Brasil), percebe-se que alguns espaços muitas vezes limitam os moradores, através de seus muros e gestão excludente. Nesta perspectiva, o objetivo principal do presente artigo foi analisar as diferentes práticas de lazer vivenciadas na Estação das Docas, além de buscar identificar e analisar se havia barreiras para a vivência do lazer, e quais seriam essas barreiras. Neste estudo, os procedimentos metodológicos incluíram a pesquisa de campo, através da observação direta e pesquisa bibliográfica, além de entrevistas semiestruturadas junto a quarenta frequentadores da Estação. Concluiu-se que as práticas de lazer na Estação eram das mais diversas, constituindo-se como um lugar para passear, namorar, apreciar o pôr-dosol e conversar nos barzinhos e restaurantes. No entanto, havia diversas barreiras para a apropriação de algumas atividades promovidas pela Estação, como cinema, teatro e outras apresentações artísticas, que eram pouco conhecidas pelos frequentadores.
\end{abstract}

Palavras-chave: Lazer; Espaços Públicos de Lazer e Turismo; Estação das Docas.

ABSTRACT - In Belém (Pará, Brazil) it is noticed that some places imply limits to their neighborhood with walls or exclusionary management. In this sense, the aim of this paper was analyze different ways of leisure offered by Estação das Docas and thereby seek to identify and analyze if there were any barriers for the people to have leisure activities and what were these barriers. The methodology included field research, using direct observation and bibliographic research and besides, the study applied forty interviews to the users of the place. It was concluded that there were a great variety of leisure practices, being a place to walk, date, watch the sunset or talk in restaurants and pubs. Otherwise it was identified some barriers at that place, as movies, theater and another cultural activities which were little known by users.

Key words: Leisure; Public Spaces of Leisure and Tourism; Estação das Docas (BelémPará, Brazil).

\footnotetext{
Formação: Graduação em Turismo (Bacharelado) pela Universidade Federal do Pará (UFPA), Especialização em Planejamento e Gestão do Turismo e do Lazer pela Universidade Federal do Pará (UFPA). Endereço físico para correspondência: Travessa Vileta, 632. Bairro: Pedreira. CEP: 66087-422 Belém - Pará (Brasil). E-mail: pablo.viana28@gmail.com

** Formação: Graduação em Educação Física (Bacharelado) pela Universidade do Estado do Pará (UEPA), Especialização em Educação e Problemas Regionais pela Universidade Federal do Pará (UFPA), Mestrado em Antropologia Social pela Universidade Federal do Pará (UFPA), Doutorado em Ciências Sociais pela Pontifícia Universidade Católica de São Paulo (PUC-SP): Professora da Faculdade de Educação Física da Universidade Federal do Pará (UFPA). Endereço físico para correspondência: Rua Augusto Corrêa, 1 - Guamá. CEP: 66075-110 - Belém - Pará (Brasil). Telefone: (91) 32017602. E-mail: lucíliasmatos@gmail.com
} 



\section{INTRODUÇÃO}

O desenvolvimento de uma cidade a partir da revitalização de espaços públicos de lazer e turismo requer planejamento comprometido com a criação de espaços verdadeiramente democráticos. Na cidade de Belém (Pará, Brasil), se percebeu que alguns desses espaços muitas vezes limitavam os próprios moradores, através de seus muros e gestão excludente.

Nesta perspectiva, considerou-se fundamental analisar as relações nos espaços revitalizados como equipamentos socioculturais e de lazer para moradores e turistas, uma vez que esses geralmente são modificados com o propósito de incluir as pessoas a partir das práticas socioculturais. No entanto, se percebe que em muitos casos, depois de transformados, estes ficam distanciados da maioria da população, sem cumprir totalmente o seu propósito inicial.

Corroborando com está análise Figueiredo (2008), destaca que muitos espaços nas cidades são revitalizados com o objetivo de promover o lazer e o turismo, mas que suas formas de promoção social, cultural e econômica limitam o uso desses espaços pela população local.

A Estação das Docas é um desses espaços. Criado em 2000, a partir de um projeto de refuncionalização de três galpões do antigo porto de Belém, é um projeto similar ao existente em Buenos Aires (Puerto Madero), contudo, obedece a uma concepção que, em certa medida, estava inibindo a frequência das camadas populares devido a sua concepção arquitetônica e aos preços dos serviços comerciais lá oferecidos (MATOS, 2010). No entanto, a partir principalmente de uma forte campanha publicitária, e de uma gradual incorporação de novos projetos culturais, a Estação das Docas além de ser reconhecida como um dos mais importantes pontos turísticos da cidade, usado frequentemente pelas camadas de renda alta, nem por isso deixa de sensibilizar as camadas populares (MATOS, 2010).

O tema proposto neste artigo teve como objetivo principal analisar as diferentes práticas de lazer vivenciadas na Estação das Docas, a fim de refletir sobre o processo de apropriação/pertencimento da população com este espaço, além de buscar identificar e analisar se havia barreiras para a vivência do lazer, e quais seriam essas barreiras. 
Para o aprofundamento teórico da análise sobre o lazer, este estudo foi amparado, principalmente, em autores como Marcellino (2007) e Bahia (2005). Estes entendem o lazer como meio de conhecer e compreender novas tradições, pois dissemina múltiplas relações de importância social, econômica e cultural, reconhecendo o lazer como fenômeno sociocultural. A importância do lazer vem revelando novos cenários, neste sentido, entram em cena os espaços públicos que, em muitos casos, configuram-se como espaços de sociabilidade das culturas.

Nessa perspectiva, alguns procedimentos metodológicos foram fundamentais na construção das bases empíricas e teóricas para a análise do problema aqui esboçado. Desenvolveu-se a pesquisa de campo através da observação direta, a partir dos seguintes procedimentos: na primeira etapa exploratória construiu-se a trajetória de investigação, na formulação do projeto e dos instrumentos de campo para a pesquisa, assim como foi realizada a pesquisa bibliográfica (MINAYO, 2010). Na fase seguinte, passou-se a frequentar a Estação das Docas para a observação direta, a partir da trajetória de pesquisa. $\mathrm{Na}$ oportunidade, as observações foram anotadas em diário de campo (MINAYO, 2010). As entrevistas semiestruturadas foram realizadas no mês de janeiro de 2015, durante duas semanas, em dias e horários diversificados, a partir de um roteiro previamente estruturado. As pessoas entrevistadas foram escolhidas aleatoriamente, sendo quarenta frequentadores da Estação, das quais 20 eram do sexo masculino e 20 do sexo feminino. Deste total, 21 pessoas eram da faixa etária entre 17 a 30 anos, sendo 10 entre 31 a 50 anos e 9 pessoas entre 51 a 70 anos. Os principais dados da pesquisa de campo foram fontes de reflexão desse artigo.

\section{DIREITO AO LAZER COMO AFIRMAÇÃO DA CIDADANIA}

O lazer como fenômeno sociocultural pode ser entendido como um conjunto de atividades culturais, entre as quais estão as práticas físico-esportivas, artísticas, sociais, intelectuais, manuais e turísticas ${ }^{1}$, em que as pessoas se envolvem com certa liberdade de escolha no seu tempo disponível das obrigações profissionais, familiares, sociais e fisiológicas, a fim de obter descanso, divertimento e desenvolvimento pessoal e social

1 O conteúdo cultural turístico não está presente na obra de Dumazedier, sendo acrescentado posteriormente, a partir do livro de Camargo (1986). 
(DUMAZEDIER, 1973). Neste processo, está presente o que Marcellino (1998) denominou como duplo processo educativo: a educação pelo lazer e para o lazer.

É importante reforçar, concordando com Gomes (2004), que o lazer é um fenômeno sociocultural que surgiu em diferentes contextos (histórico, social e político), e que se apresenta de forma dinâmica e diversa, de acordo com o grupo social de referência, além de ser um fenômeno complexo, pois é gerado em meio a conflitos, tensões e contradições.

Portanto, deve-se entender o lazer pelos diversos ângulos da sociedade, uma vez que propicia variadas práticas culturais dentre elas “o jogo, a brincadeira, a festa, o passeio, a viagem, o esporte e também as formas de arte (pintura, escultura, literatura, dança, teatro, música, cinema), dentre várias outras possibilidades" (GOMES, 2004, p. 124).

O lazer é um direito social assegurado na chamada Constituição cidadã, de 1988, por isso é compreendido como um "bem social, um direito do cidadão e um instrumento essencial à apropriação da cidade por toda sociedade" (MATOS, 2001, p. 119).

No entanto, há uma lacuna entre o que está escrito e o que é assegurado para a sua vivência. Existem diversas barreiras para que o lazer seja, de fato, assumido como direito social, entre eles estão o acesso aos espaços e equipamentos públicos de lazer, e uma política mais inclusiva de lazer.

Bahia (2005) expõe que o lazer ainda se apresenta como não prioritário nas vidas das pessoas, uma vez que o trabalho torna-se o mais importante em sua rotina. Portanto, é importante que a população veja o lazer como um direito básico de prazer e felicidade. Muitas das vivências de lazer passam despercebidas, pois a pessoas não identificam certas atividades como sendo práticas de lazer.

De fato, a observação da prática do lazer na sociedade moderna é marcada por fortes componentes de produtividade. Valoriza-se a "performance", "o produto e não o processo de vivência que lhe dá origem, estimula-se a prática compulsória de atividades denotadoras de moda" ou "status" (MARCELLINO, 1987, p. 28).

Nessa perspectiva, percebe-se que o lazer está muito mais voltado aos serviços do mercado, no qual é visualizado como objeto de alienação e dominação por uma produção voltada aos interesses do capital. Nesse sentido, Bahia (2005) aponta que as vivências de lazer devem ser pautadas na vida real e no cotidiano das pessoas. 
A proposta de vivência do lazer é de uma reflexão que se paute em muito mais do que numa lógica de compensação, de alienação ou de exploração do mercado ao qual este é submetido. Um lazer marcado pela criticidade e criatividade, alicerçado no objetivo de Denúncia de uma realidade historicamente construída e no anúncio de uma utopia focada na mudança do possível, a ser alcançado dentro de nossas vidas (BAHIA, 2005, p. 14).

Marcellino (2007) expõe algumas barreiras que impedem a democratização do lazer pelo lugar público. Esses obstáculos são de caráter social, grau de instrução, de faixa etária e de gênero, além de colocar o lazer como produto a ser vendido. De fato, as barreiras vão surgindo com a dinâmica do espaço, seja no espaço público ou públicoprivado, como observado na maioria dos lugares que proporcionam lazer para os cidadãos.

Marcellino (2007) destaca a existência de alguns equipamentos não específicos de lazer, dentre eles a rua e o lar. Esses lugares são espaços de intensa vivência do lazer, no entanto, as políticas públicas ainda não tomaram como canal de transformação de ações voltadas às práticas do lazer, e pouco se observa nas mídias televisivas programas que estimulem, por exemplo, aprendizados para o esporte educacional e de lazer, leitura, filmes educativos etc. No mesmo caminho estão as ruas, enquanto locais de interação de crianças, jovens e até mesmo adultos, que em muitos casos tornam-se ambientes limitadores das vivências de lazer, pois não se criam espaços com o intuito de atender a todos, e quando esses lugares existem, como as academias ar livre ou parques infantis, duram pouco tempo, por não terem a manutenção adequada, além do que, a população não é ouvida no planejamento desses lugares, limitando as possibilidades de relações de pertencimento das pessoas com os espaços e equipamentos criados e ou revitalizados.

As escolas também podem ser compreendidas como espaços de vivências de educação pelo e para lazer, uma vez que as possibilidades de utilizar esses locais são grandes, pois apresentam vários espaços como quadra esportiva, auditório, salas de aulas e bibliotecas. Disseminar as práticas de lazer em ambientes como esses é transformar pessoas mais reflexivas, já que a educação pelo lazer estará sendo concretizada. Por outro lado, observam-se, ainda, barreiras no uso desses espaços, principalmente quando se referem à participação efetiva das comunidades do entorno, que muitas vezes são vistas com preconceito, como bem coloca Bahia (2005, p. 15): 
É através da vivência do lazer que surge a possibilidade de aprender a usufruí-lo em um dos níveis (elementar, crítico ou criativo), optar pelo gênero (vivência prática de uma atividade, busca por conhecimento sobre a atividade ou escolha por assistir a um espetáculo), bem como de conhecer seus diversos conteúdos culturais e ter autonomia para escolher um deles.

Portanto, é de suma importância o desenvolvimento do lazer a partir da participação popular, políticas de acesso, democratização de espaços públicos, uma educação pelo e para o lazer, construção e manutenção de equipamentos de lazer e a compreensão do lazer como direito social.

Nessa perspectiva, o debate acerca da cidadania e dos direitos sociais vem contribuir em várias questões da sociedade atual, dentre estas, as formas de acesso e participação. Tendo em vista a importância dessas temáticas no complexo processo de planejamento e gestão de espaços públicos de lazer, faz-se necessário um debate visando trazer reflexões e contribuições para uma sociedade que se apresenta como desigual e contraditória.

Buscar descrever o conceito de cidadania não é tarefa fácil, uma vez que se trata de um assunto complexo e bastante debatido por vários setores da sociedade. Milton Santos (2007, p. 82) salienta que a "cidadania é uma lei da sociedade que, sem distinção, atinge a todos e investe cada qual com a força de se ver respeitado contra a força, em qualquer circunstância". Como bem coloca o autor a cidadania se aprende, ou seja, independente de definições abstratas criadas em tempos e lugares diferentes, a cidadania, tem que ser reclamada.

Em uma visão moderna sobre a cidadania, Gomes, Pinheiro e Lacerda (2010) elaboram dois conceitos importantes: um está diretamente ligado ao desenvolvimento dos Estados-nação e o outro diz respeito à relação dos indivíduos com o Estado. Vale destacar também que o conceito de cidadania na modernidade está elencado por três grupos de direitos - o civil, o político e o social.

[...] a cada um destes elementos corresponde um conjunto de direitos. A saber, a cidadania civil é formada pelos direitos necessários à liberdade individual; a cidadania política pelos direitos de participação no exercício do poder político; e a cidadania social pelo conjunto de direitos, que inclui segurança e bem-estar econômico, o direito de compartilhar a riqueza socialmente produzida e o de viver uma vida civilizada, segundo os padrões sociais vigentes (SILVA, 2000, p. 127). 
Gomes, Pinheiro e Lacerda (2010) expõem que os direitos civis são caracterizados pelas liberdades individuais, liberdade de opinião, direito à propriedade e ao acesso à justiça. Já os direitos políticos consistem na participação do processo político. No que se refere aos direitos sociais, estão o trabalho, a saúde, a educação e o lazer, que são essenciais para vida em sociedade, ou seja, são de suma importância na concretização da cidadania. Deve-se pensar a cidadania a partir da inclusão social, do acesso a todos os direitos supracitados, e que esteja ligada à perspectiva de um sentimento comunitário.

[...] pertencimento a uma comunidade que lhe confere deveres, bem como direitos a serem reivindicados, possibilitando a alteração e redefinição das relações no interior dos grupos sociais, abordando interesses e aspirações conflitantes em prol da construção do bem-estar coletivo (GOMES; PINHEIRO; LACERDA, 2010, p. 33).

Mascarenhas (2004), em seu artigo "Lazerania também é uma conquista", apresenta reflexões acerca do lazer como um direito social, e salienta as transformações sociais em curso, em que o jogo político desintegra os direitos sociais. O autor destaca também as mudanças frente aos efeitos excludentes das políticas neoliberais - o chamado "Mercolazer", que consiste na relação de venda e troca efetuada no mercado.

[...] um valor de troca, o "salto perigoso" em direção ao equivalente geral, momento final do giro do capital em que se resgata a mais-valia e se conferem os lucros, objetivo essencial da crescente e heterogênea indústria do lazer (MASCARENHAS, 2004, p. 80).

Esta nova forma de fazer lazer pelo meio mercadológico traz como efeito o não direito, pois estabelece o acesso principalmente a quem tem poder financeiro. Este aspecto é visível em um espaço como a Estação das Docas, que mesmo oportunizando o acesso de livre entrada, ainda assim as barreiras continuam e estão engendradas fundamentalmente no alto custo dos restaurantes, bares e lojas, pois as pessoas das classes populares e mesmo as das classes médias e com isso grande parte também de turistas não têm a oportunidade de usufruir por completo do lugar, que se diz público.

Portanto, é importante pensar em modelos de lazer para todos, e não apenas para uma minoria, por meio de políticas públicas, buscando estabelecer formas de acesso aos vários espaços e equipamentos de lazer a todas as classes sociais. Em contrapartida ao 
movimento do "Mercolazer", Mascarenhas (2005, p. 160) aponta um novo projeto em formação a "Lazerania", que consiste em:

[...] expressar a possibilidade de apropriação do lazer como um tempo e espaço para a prática da liberdade, para o exercício da cidadania, busca traduzir a qualidade social de uma sociedade cujo direito ao lazer pode ter seu reconhecimento alicerçado sobre princípios como planificação, participação, autonomia, organização, justiça e democracia, deixando de ser monopólio ou instrumento daqueles que concentram poder econômico.

Pode-se afirmar que a importância dos direitos sociais para o exercício da cidadania é de grande relevância para os grupos sociais. Portanto, as questões de acesso, assim como a participação, são de fundamental importância para o desenvolvimento pautado na igualdade e nos direitos sociais. Bordenave (1994) declara que participação advém da palavra parte, ou seja, a sociedade tem que fazer parte, tomar parte e ter parte na construção da cidadania. Nesta perspectiva, se não houver uma aproximação da sociedade com o planejamento urbano,

[...] além de impedir a formação de um compromisso social em torno da política que se pretende estabelecer, enfraquece a efetividade do projeto urbano pela sua falta de adaptação à realidade a qual vai ser aplicado (RIBEIRO, 2012, p. 87).

Dentre as leis da política urbana está o estatuto da cidade que tem como objetivo: garantir o direito à cidade como um dos direitos fundamentais da pessoa humana, para que todos tenham acesso às oportunidades que a vida urbana oferece. A legislação urbanística, por meio do Estatuto da Cidade (Lei no 10.257/2001), garante a participação popular, como citado no Art. $2^{\circ}$, Cap. II:

[...] gestão democrática por meio da participação da população e de associações representativas do vários segmentos da comunidade na formulação, execução e acompanhamento de planos, programas e projetos de desenvolvimento urbano.

Embora a participação da população esteja estabelecida em lei, ainda se percebe o não envolvimento dos sujeitos sociais nas ações das políticas públicas. E quando acontece, é de forma "consultiva", como nos fóruns, conselhos e plenárias. Precisa-se avançar na questão da participação, posto que ainda se apresenta de forma muito tímida a inclusão da sociedade no planejamento das cidades. Todavia, não se pode esquecer 
que a maioria da sociedade ainda esbarra no acesso ao conhecimento crítico da realidade. Este fato é caracterizado por uma educação sem qualidade, ou seja, enquanto houver problemas estruturais na base da sociedade, é impossível criar alicerces concretos na busca de igualdade e de direitos sociais.

No entanto, ainda há muito a ser desenvolvido. Na prática, percebe-se a existência de espaços públicos transformados em espaços privatizados, acentuando uma segregação social e econômica. Desse modo, pode-se aportar o grande desafio da gestão pública em dinamizar os espaços públicos para toda a sociedade, pois, esses lugares apresentam manifestações políticas, artísticas e econômicas. Neste sentido, é importante uma política voltada às questões de acesso e à participação na construção de lugares sociáveis.

\section{PLANEJAMENTO DOS ESPAÇOS PÚBLICOS DE LAZER}

No que se refere ao planejamento dos espaços de lazer e do turismo, é preciso diagnosticar os perfis da população e a sua aceitação aos espaços públicos de lazer e turismo. Isso se dá pelo planejamento, ao entender as especificidades regionais e identificar fatores regionais que contribuam para o desenvolvimento local. Por isso, é importante pensar uma gestão pública atrelada às políticas setoriais, a fim de trazer benefícios tanto para população local quanto para o visitante.

Conceição e Nuñes (2007, p. 11) salientam que o processo de planejamento está fundamentado pela indagação valorativa, que "tem uma grande capacidade de exprimir as reais preocupações e aspirações coletivas dos atores sociais que tomam consciência de seus problemas e se empenham em resolvê-los de maneira conjunta”. Neste sentido, é importante frisar que essa indagação valorativa é um método técnico que se estabelece pela prática da cooperação, frente aos modelos tradicionais de planejamento.

No contexto do planejamento do turismo, Cruz (2006) vem mostrar as convergências e contradições da produção do espaço, tomado pelas políticas públicas de turismo como forma de desenvolvimento. Entretanto, a autora salienta as duas características intrínsecas do turismo - a primeira retrata a atividade turística como prática social; e, por outro lado, o turismo utiliza o espaço como objeto de consumo. 
Dentre essas características, devem-se pontuar as práticas sociais, pois são as relações sociais que dão um sentido ao desenvolvimento do turismo, ou seja, quando se pensa em planejar a atividade turística, precisa-se compreender toda a realidade local. Como salienta Hall (2001, p. 55), o planejamento turístico deve ser baseado nas metas e prioridades dos residentes.

De acordo com Ribeiro (2012), o conceito de espaços públicos vem sendo desenvolvido na perspectiva da multidisciplinaridade, já que os trabalhos produzidos são fundamentalmente espaciais, pois englobam processos políticos, culturais, econômicos e de expressões espaciais. Conforme Leite (2001, p. 116), o que diferencia os espaços públicos são os:

[...] sentidos de lugar e pertencimento a certos espaços urbanos, e, de outro modo, essas espacialidades incidem igualmente na construção de sentidos para as ações, os espaços urbanos podem se constituir como espaços públicos: locais onde as diferenças se publicizam e se confrontam politicamente.

Nas ciências sociais, os espaços públicos podem ser entendidos como lugares de convivência que expressam estilos de vida, relações de poder e formas de apropriação por distintos grupos sociais, ou seja, lugares que apresentam uma representatividade da vida e da história das cidades (ANDRADE; JAYME; ALMEIDA, 2009).

Nessa perspectiva, ressalta-se a importância do planejamento em espaços públicos de lazer e do turismo a partir da participação. Também é necessário refletir sobre os pontos cruciais na reconfiguração de ambientes socialmente construídos, posto que às vezes tornam-se "privatizados" ou mesmo "turistificados".

O termo "turistificação" significa criar espaços para atividade turística, porém esses espaços não podem ser limitados a uma parte da sociedade (FIGUEIREDO, 2008). Telles e Gândara (2014) salientam que o processo de turistificação está relacionado com as concepções de território, de ambiência relacional, de patrimônio e de lugar, dentro da consideração assumida pelo processo histórico do presente.

Os espaços públicos de lazer e turismo são importantes para a vivência democrática das práticas culturais de lazer, visto que esses ambientes, principalmente quando planejados coletivamente, possibilitam uma relação de pertencimento dos moradores e turistas com os espaços. Neste sentido, exercer o planejamento com 
participação nas questões da cidade implica envolver o social, o simbólico e cultural dos lugares, estabelecendo vínculos com a população através do lazer e da atividade turística.

\section{RESULTADOS E DISCUSSÕES: LIMITES E POSSIBILIDADES DAS PRÁTICAS DE LAZER NA ESTAÇÃO DAS DOCAS}

Inaugurado em 13 de maio de 2000, pelo governo do estado do Pará, o Complexo Turístico e Cultural "Estação das Docas" está localizado às margens da Baía do Guajará (TRINDADE JR; AMARAL, 2006). O espaço ocupa uma área de 32.000 $\mathrm{m}^{2}$, divididos em três galpões, denominados: Boulevard das Artes, Boulevard da Gastronomia e Boulevard das Feiras e Eventos, além do terminal fluvial de passageiros e do anfiteatro (TRINDADE JR; AMARAL, 2006). A administração do complexo é composta pela Organização Social Pará 2000, criada em 25 de janeiro de 2000, por meio do Decreto $n^{\circ}$ 3.881, esta Organização Social é uma entidade sem fins lucrativos, de direito privado, destinada à promoção de cultura, lazer e turismo.

Os dados que serão analisados nesse tópico são resultantes do trabalho de campo realizado nos meses de novembro e dezembro de 2014, e janeiro de 2015, no qual delimitou-se a trajetória da pesquisa através da pesquisa exploratória, e posteriormente realizou-se a observação do espaço social Estação das Docas, as observações foram sistematizadas em caderno de campo. Em janeiro de 2015 foram realizadas as entrevistas, durante duas semanas, estabelecendo-se dias e horários diversificados, a partir de um roteiro previamente estruturado, sendo que as entrevistas semiestruturadas se deram em diferentes lugares dentro da Estação das Docas (Museu do Porto, bares, restaurantes, orla e teatro). 


\subsection{ANÁLISE DAS ENTREVISTAS: PRINCIPAIS PRÁTICAS DE LAZER NA ESTAÇÃO DAS DOCAS E AS BARREIRAS QUE IMPEDEM O SEU USUFRUTO PLENO}

Durante a pesquisa de campo, foram identificados os diferentes perfis dos usuários, segundo as variáveis de sexo, ocupação, escolaridade e renda. As pessoas entrevistadas foram escolhidas aleatoriamente, sendo quarenta frequentadores da Estação. Os dados obtidos por meio de entrevistas revelaram as características de um público diversificado que frequentava a Estação das Docas.

Dentre as ocupações mais citadas entre os entrevistados foram: estudantes, professores e vendedores. No universo de 40 entrevistados, quanto à escolaridade, 17 pessoas mencionaram ter formação em nível superior, 21 pessoas haviam completado o ensino médio e 2 pessoas o ensino fundamental completo. De acordo com essas informações, considerou-se pertinente situar que a metade dos entrevistados declarou ter curso superior completo, configurando um percentual bastante expressivo, uma vez que, segundo o Instituto Brasileiro de Geografia e Estatística - IBGE (2010), mais da metade $(56,4 \%)$ da população paraense de 25 anos ou mais não havia concluído o ensino fundamental, enquanto apenas 6,2\% tinham graduação em nível superior.

Quando perguntado "com que frequência você visita este espaço", 14 dos entrevistados afirmaram que iam à Estação das Docas uma vez na semana, 8 pessoas uma vez ao mês e 8 frequentemente visitavam o espaço, além de 10 pessoas que frequentava em intervalos de tempo diferentes (uma vez ao ano, três vezes ao mês etc.). Pôde-se observar haver um grande percentual que configurou a frequência de 1 vez na semana, porém, esta característica advinha de algumas peculiaridades que serão salientadas mais adiante.

Ao observar o quesito renda, foi possível identificar que havia pessoas com níveis salariais diversos frequentando a Estação das Docas. Do percentual de quarenta entrevistados 13 pessoas recebiam acima de 1 salário, 13 pessoas acima de 3 salários e 5 pessoas recebiam entre 7 e 10 salários, o restante dos entrevistados estavam estudando ou desempregados.

Considerou-se importante analisar a frequência de diferentes grupos sociais, a partir dos dados de escolaridade, faixa etária e renda, sendo possível afirmar que havia 
uma apropriação inversa do espaço. No caso em estudo, nos primeiros anos após a inauguração da Estação das Docas, o espaço era frequentado hegemonicamente por pessoas com maior poder aquisitivo (TRINDADE JR; AMARAL, 2006). Fato que levou este espaço a ser reconhecido por muitos como "Estação das Dondocas". Porém, desde a inauguração no ano 2000 diferentes administrações passaram pelo espaço e uma série de estratégias foram criadas com vista a tornar o espaço uma referência para os cidadãos paraenses e para os turistas, entre as quais se podem citar as campanhas publicitárias e propagandas e os investimentos em eventos diversificados, de modo que, ainda de forma limitada, a Estação vem se configurando como um lugar com maior diversidade de frequentadores.

Observou-se que nenhum dos entrevistados estava pela primeira vez na Estação. Este dado revelou que as pessoas visitaram a Estação pela primeira vez e voltaram. Ainda que timidamente, as pessoas vinham usufruindo do espaço, como expressou o interlocutor 11: "um bom lugar para passear, sentir o vento da maré, um lugar agradável; é um lugar que eu acho bem legal, que eu gosto de estar"2. Muitos entrevistados fizeram alusão ao contato com o rio, com a natureza, e percebeu-se sempre um ar de orgulho por estar ali. Como salienta Malheiros (2009, p. 72), a revitalização de edificações históricas à beira-rio, fortalece as raízes e a autoestima da população. No caso de Belém há poucos espaços de lazer na beira do rio, o que leva as pessoas a frequentar a Estação, principalmente pela quebra das barreiras e contradições sobre o uso do espaço.

Quanto à proveniência dos frequentadores, as respostas foram as mais variadas, pessoas oriundas dos mais variados bairros: Jurunas, Terra Firme, Pratinha, Batista Campos e Umarizal, além de outras cidades como Ananindeua e Marituba. Percebeu-se que foram citados os diferentes bairros da capital paraense, tanto centrais quanto periféricos, além de cidades da região metropolitana de Belém.

Em resposta à pergunta “O que lhe motiva a vir à Estação das Docas?”, grande parte dos entrevistados afirmou que havia vindo pela tranquilidade, pela natureza, por ser um lugar agradável e pelo lazer. Notou-se que o espaço estava tomando novos contextos e atribuições, olhando para o passado, quando o espaço se apresentava com mais nitidez como "lugar de consumo" e "consumo de lugar", ou seja, "as

\footnotetext{
${ }^{2}$ Entrevista concedida em 09/01/2015.
} 
especificidades do lugar (beira-rio), seu valor de uso, que se transforma em valor de troca, sem deixar de ser valor de uso" (AMARAL; VILAR, 2005, p. 107). Nesta afirmação dos autores é perceptível ainda esses valores pelo lugar, seja pelo uso ou pela troca. Ainda sobre a pergunta acima, na fala do frequentador 12, pôde-se observar o quanto a Estação das Docas possibilitava resgatar os laços culturais:

Para mim é um espaço de lazer, eu gosto do verde, gosto de água desde criança, é natural pra mim. Pra mim foi uma questão natural mesmo, mais para olhar mesmo a natureza, principalmente a água (falando da baía em frente) e o verde das ilhas.

Dentre as respostas da pergunta acima, pouco se comentou sobre os equipamentos internos da Estação, como restaurantes, bares, lojas, sorveteria entre outros. Acredita-se que isso ficou caracterizado pelo alto valor cobrado pelos serviços e produtos nesses lugares. Para a maioria dos entrevistados, a motivação dizia respeito a questões da cultura e da natureza. Ao analisar essas motivações considerou-se ter ficado claro o quanto o espaço "Estação das Docas" permanecia com um modelo segregador, em que apenas uma parte da sociedade tinha o total usufruto dos equipamentos internos (lojas, bares, restaurantes, cinema), ou seja, esse processo foi marcado pela renovação de espaços urbanos acompanhada pela refuncionalização e reapropriação por atores responsáveis pela elitização do mesmo - a chamada gentrificação (SÁNCHEZ, 2003).

Segundo Amaral e Vilar (2005), a "estação" foi criada a partir de um modelo de gestão urbana pautada em intervenções. Essa prerrogativa é caracterizada por um modelo estratégico que envolve uma tendência a "manipulação", , isto é, a população foi induzida a aceitar a criação do complexo por diferentes meios de propagadas maciças como estratégias de aceitação e adesão. Constatou-se que ainda estava havendo certa dificuldade de acesso da população de Belém e de turistas aos diversificados espaços e programações culturais da Estação, como cinema, teatro, apresentações artísticas etc. Essa limitação, supostamente foi caracterizada pela má divulgação acarretando em parte o desconhecimento de muitas das programações e por uma ainda, limitada relação de

\footnotetext{
${ }^{3}$ Situações em que a população é induzida a aceitar determinada intervenção, por meio de propagandas maciças e outros mecanismos. O Estado, para não usar a força física/bruta, busca outros mecanismos de convencimento, ressaltando-se que o diálogo não é estabelecido verdadeiramente (AMARAL; VILAR, 2005, p. 105).
} 
pertencimento das pessoas ao espaço como um todo, o que também estaria intimamente relacionado a uma forma de gestão muito pouco participativa.

Quanto à pergunta "Quais as maiores dificuldades que você encontra para ter acesso às atividades de lazer existentes na Estação das Docas?”. A maioria relatou não ter nenhum problema em relação às atividades, no entanto, ao se perguntar sobre quais as atividades existentes, ficou evidente que o conhecimento dos frequentadores ainda era bastante limitado. A partir de algumas entrevistas, se teve como constatar essas barreiras:

Tem teatro, às vezes passa filme, às vezes shows como esse (falando do carimbó), feiras que na verdade não sei se está para lazer ou cultura, mas acontecem várias feiras também aqui, acho que é isso, de lazer seria isso (FREQUENTADOR 13). ${ }^{4}$

Acabei de descobrir mais uma que foi o cine, não sabia mais de nenhuma, a não ser curtir a paisagem e comer, por exemplo (FREQUENTADOR 31). ${ }^{5}$

Eu sei que tem dia de sexta-feira, o carimbó, e algumas apresentações, dia de sexta-feira, agora durante a semana eu não sei (FREQUENTADOR 33). ${ }^{6}$

Esses obstáculos foram citados de forma constante nas entrevistas. Dentre os projetos promovidos pela "Estação das docas", o único mais comentado foi o "Por-doSom", que acontecia às sextas-feiras, o "Carimbó", assim chamado pelos entrevistados, foi o mais lembrado, em virtude da entrevista ter sido realizada em uma sexta-feira. Dos 40 entrevistados 6 pessoas referiram a palavra teatro, porém nenhum entrevistado citou o projeto "Pôr-do-Sol", que ocorria em domingos alternados no terminal fluvial, e às vezes no anfiteatro. Os shows artísticos apareceram como uma das atividades conhecidas pelos frequentadores, e o cinema foi lembrado por uma pequena parcela de 5 dos entrevistados.

Foram obtidas respostas em que os entrevistados não sabiam de nenhuma atividade de lazer promovida pela "Estação das Docas", como se pôde perceber em algumas falas:

\footnotetext{
${ }^{4}$ Entrevista concedida em 09/01/2015.

${ }^{5}$ Entrevista concedida em 14/01/2015.

${ }^{6}$ Entrevista concedida em 14/01/2015.

${ }^{7}$ Projeto realizado pela Organização Social Pará 2000, que gerencia o Complexo Estação das Docas.
} 
Olha, eu sei que tem passeio né, mais nunca fui também. Eu só venho pra cá para descansar mesmo (FREQUENTADOR 25). ${ }^{8}$

Olha, eu não sei muito bem, acredito que tenha viagem de barco, né; e o buffet, não sei das outras coisas que tem (FREQUENTADOR 36). ${ }^{9}$

Foi possível notar o quanto as pessoas que frequentavam o espaço ainda não conheciam os projetos da "Estação". Essas barreiras aconteciam por diversos motivos, o primeiro, por suposição, estaria relacionado à divulgação de tais projetos. Julgou-se pertinente ressaltar que a Pará 2000, empresa administradora do espaço, tinha funcionários das áreas de marketing, propaganda, publicidade e jornalismo, mas, ao que pareceu, pouco havia feito para a divulgação das ações culturais do espaço. A única ferramenta visível durante a pesquisa em relação à divulgação dos projetos foi por meio da página da estação na web e o facebook, pouco através das mídias televisivas e de panfletos dentro do espaço. ${ }^{10}$

A pesquisa de opinião realizada pela "Estação das Docas" em 2014 também corroborou com este estudo, pois revelou que os frequentadores pouco conheciam dos projetos culturais do espaço, como o Cine Estação, Pôr-do-Som, Pôr-do-Sol e Palco Deslizante. Supôs-se que este fato mostrou o quanto estava deficiente a divulgação das ações culturais da estação, criando empecilhos ao usufruto do espaço e programações pelos usuários.

Em relação às atividades de lazer apontadas pelos 40 entrevistados, 8 pessoas usavam o espaço para passear, 10 pessoas frequentavam os restaurantes e os bares, 6 frequentavam o cinema e teatro, 6 pessoas iam aos shows culturais e a outra porcentagem utilizavam para o turismo, compras e exposições. Segundo Barbalho e Freitas (2011, p. 138), os equipamentos culturais são pautados em políticas de intervenção, cuja concepção tradicional é:

[...] a vinculação destes espaços com esferas mais elitizadas da sociedade acabam por beneficiar aqueles que já são usuários de equipamentos similares e distanciam os que entendem este tipo de espaço e de prática como distante de sua realidade cotidiana.

\footnotetext{
${ }^{8}$ Entrevista concedida em 10/01/2015.

${ }^{9}$ Entrevista concedida em 14/01/2015.

${ }^{10}$ Observações feitas por meio de diário de campo durante os seis meses da pesquisa, no período de julho de 2014 a janeiro de 2015.
} 
A partir do que foi visto, pode-se afirmar que se teve como constatar o quanto as práticas de lazer dentro do espaço turístico e cultural "Estação das Docas", ainda eram um limitador, com relação aos projetos do complexo. Por outro lado, se pôde observar uma maior aproximação da população junto ao espaço, ainda que de forma tímida, mas que aos poucos estava se apropriado do lugar por meio de diferentes atividades de lazer, como passear, namorar, apreciar o pôr-do-sol, assistir shows e até mesmo consumir.

Embora o lazer seja um direito social que deveria ser garantido pelo Estado, este investiu muito pouco em uma concepção de espaço público de lazer, conforme foi comprovado na pesquisa. Seria preciso haver um planejamento que envolvesse a comunidade desde a sua criação até a sua gestão, pois, como visto pouco se observou em relação aos aspectos do acesso pleno das práticas de lazer e participação na gestão, tendo como resultado a falta de uma maior relação de pertencimento nas práticas de lazer, assim como no usufruto pleno das atividades de lazer proporcionadas naquele espaço.

\section{CONSIDERAÇÕES FINAIS}

A Estação das Docas é um dos espaços de lazer e turismo que mais recebe visitantes na cidade de Belém. Conhecida como um cartão-postal teve a sua concepção inicial focada na conjuntura do planejamento estratégico visando auferir uma frequência de pessoas com maior poder aquisitivo no espaço e um perfil que se pautava na atividade turística.

Nesta pesquisa, objetivou-se entender as diferentes práticas de lazer, assim como averiguar as barreiras existentes em relação a essas vivências. Como visto, no que tange ao conceito de "lazer", a noção dos frequentadores ainda estava limitada. Com relação à existência de barreiras para a vivência plena do lazer, foi possível perceber que elas ainda eram numerosas, visto que essas dificuldades estavam atreladas à concepção do espaço quando este não teve a participação da população no processo de construção, assim como não se teve uma gestão que envolvesse esse público no planejamento. Esse processo histórico-cultural tinha influenciado uma participação tímida dos usuários às ações de lazer dentro do espaço da Estação.

Analisando o lazer pelo seu aspecto econômico, social e cultural, tornaram-se visíveis as dificuldades em relação às práticas do lazer. Uma delas se referiu a barreira 
interclasses sociais, devido a diversos fatores presenciados no espaço analisado. Dentre as barreiras, percebeu-se o quanto a "Estação das Docas" ainda estava se apresentando em um contexto segregador, reproduzindo obstáculos, pelo modelo pautado na falta de participação dos frequentadores no planejamento do espaço, um aspecto limitador do acesso a algumas atividades dentro do espaço, sendo que os espaços públicos de lazer devem propiciar mudanças alcançáveis nas vidas das pessoas.

Conforme averiguado, foram encontradas várias barreiras no usufruto das atividades de lazer na Estação, sendo que essas limitações advieram de um processo sociopolítico em torno da reconfiguração do espaço, apontado pelas diversas pesquisas realizadas sobre a "Estação das Docas", e entre as questões evidenciadas nas entrevistas e nas observações em campo durante esta pesquisa.

Pôde-se perceber, ainda, que havia várias barreiras que tornaram-se visíveis a partir das falas dos entrevistados, e quando confrontadas com a pesquisa de opinião sobre o espaço, realizada em 2014, cuja divulgação ainda era um dos obstáculos citados pelos usuários, por não conhecerem os projetos vinculados àquele complexo.

Soluções alcançáveis poderiam ser executadas no espaço, conforme averiguado durante a pesquisa de campo, de acordo com que foi observado na "Estação das Docas", a mesma apresentava instrumentos importantes de divulgação dentro do próprio ambiente, como os alto falantes que poderiam muito bem ser utilizados para a promoção e anúncio de toda a programação existente no espaço, mecanismo como esse poderia ajudar na difusão dos projetos culturais do lugar.

Outra problemática esteve relacionada aos equipamentos de entretenimento dentro do espaço, devido aos custos altíssimos, que acabavam limitando o usufruto do lugar tanto pelos moradores de Belém e da região metropolitana, até os visitantes de outros estados e países, visto que parte apenas estava usufruindo o espaço para contemplação do "rio" e da paisagem, como salientado na pesquisa.

Destarte, o processo de inclusão da sociedade nas questões referentes ao acesso e participação ainda estava carecendo de atenção, uma vez que, enquanto houver limitações ao uso dos espaços do complexo pelos moradores e visitantes, vão continuar existindo as diversas barreiras nas práticas de lazer em um espaço que se considera público. 


\section{REFERÊNCIAS}

AMARAL, M. D. B.; VILAR, B. S. A cidade estratégica nas políticas de renovação urbana em Belém: a experiência da Estação das Docas. In: TRINDADE JÚNIOR, S. C; SILVA, M. A. P. (Org.). Belém: a cidade e o rio na Amazônia. Belém: EDUFPA, 2005.

ANDRADE, L. T.; JAYME, J. G.; ALMEIDA, R. C. Espaços públicos: novas sociabilidades, novos controles. Cadernos Metrópole, São Paulo, n. 21, p. 131-151, 2009.

BAHIA, M. C. O. Lazer - meio ambiente: em busca das atitudes vivenciadas nos Esportes de Aventura. 2005. Dissertação (Mestrado em Educação Física) Universidade Metodista de Piracicaba, Piracicaba, 2005.

BARBALHO, A.; FREITAS, A. P. N. Política cultural e consumo na região amazônica: um estudo dos públicos da Estação das Docas em Belém do Pará. Revista Alceu, v. 12, n. 23, p. 130-142, 2011.

BORDENAVE, J. E. D. O que é participação. São Paulo: Brasiliense. 1994. (Coleção Primeiros Passos, 95).

BRASIL. Lei Federal n. 10.257 de 10 de julho de 2001. Estatuto da Cidade Disponível em: <http://www.planalto.gov.br/ccivil_03/leis/leis_2001/110257.htm>. Acesso em: 30/11/2014.

CAMARGO, L. O. L. O que é lazer? São Paulo: Brasiliense, 1986.

CONCEIÇÃO, R. J.; NUÑEZ, B. E. C. Planejamento participativo e desenvolvimento regional sustentável: uma análise de método aplicativo na Região Metropolitana de Curitiba (RMC). In: SEMINÁRIO NACIONAL PAISAGEM E PARTICIPAÇÃO: PRÁTICAS NO ESPAÇO LIVRE PÚBLICO, 2007. São Paulo. Anais... São Paulo: FAU/USP, 2007.

CRUZ, R. C. A. Planejamento governamental do turismo: convergências e contradições na produção do espaço. 2006. Disponível em: <http://www.udc.edu.br/posgraduacao/turismo/Rita\%20-

\%20Planejamento\%20Governamental.pdf>. Acesso em: 30/11/2014.

DUMAZEDIER, J. Lazer e cultura popular. São Paulo: Perspectiva. 1973.

FIGUEIREDO, S. L. Espaços públicos nas cidades: notas sobre o ordenamento, acessibilidade e turistificação. In: FIGUEIREDO, S. L. (Org.). Turismo, lazer e planejamento urbano e regional. Belém: NAEA/UFPA; ANPUR, 2008.

GOMES, C. L. Verbetes Lazer - concepções. In: GOMES, C. L. (Org). Dicionário crítico do lazer. Belo Horizonte: Autêntica, 2004. 
GOMES, C.; PINHEIRO, M.; LACERDA, L. Lazer, turismo e inclusão social: intervenção com idosos. Belo Horizonte: UFMG, 2010.

HALL, C. R. Planejamento turístico: políticas, processos e relacionamentos. São Paulo: Contexto, 2001.

LEITE, R. P. Espaço público e política de lugares: usos do patrimônio cultural na reinvenção contemporânea do Recife Antigo. 2001. Tese (Doutorado) - Universidade Estadual de campinas, Campinas, 2001.

MALHEIROS, B. C. P. Portos, portas e postais: experiências, discursos e imagens produzindo a orla fluvial de Belém (PA). Dissertação (Mestrado em Planejamento do Desenvolvimento)- Universidade Federal do Pará, Belém, 2009.

MARCELLINO, N. C. Lazer e educação. Campinas: Papirus, 1987. 1998.

Lazer: concepções e significados. Licere, Belo Horizonte, v. 1, n. 1, p. 37-43, Algumas aproximações entre lazer e sociedade. Animador Sociocultural: Revista Iberoamericana, v. 1, n. 2, p. 1-20, 2007.

MASCARENHAS, F. "Lazerania" também é conquista: tendências e desafios na era do mercado. Revista Movimento, Porto Alegre, v. 10, n. 2, p. 73-90, maio/ago. 2004.

MASCARENHAS, F. Entre o ócio e o negócio: teses acerca da anatomia do Lazer. 2005. 308 f. Tese (Doutorado em Educação Física) - Faculdade de Educação Física, Universidade Estadual de Campinas, Campinas, 2005.

MATOS, L. S. Belém do direito ao lazer ao direito a cidade. In: MARCELLINO, N. C. (Org.). Lazer\& Esporte: políticas públicas. Campinas. Autores Associados, 2001.

MATOS, L. S. Belém em festa: a economia lúdica da fé no Círio de Nazaré. 2010. 280 f. Tese (Doutorado em Ciências Sociais) - Programa de Estudos em Pós-Graduação em Ciências Sociais, Pontifícia Universidade Católica de São Paulo, São Paulo, 2010.

MINAYO, M. C. S. Pesquisa Social: teoria, método e criatividade. 29 ed. Petrópolis: Vozes, 2010.

PARÁ. Decreto n ${ }^{\circ} 3.881$, de 25 janeiro de 2000. Qualifica como Organização Social a Sociedade Civil Pará 2000. Disponível em: <http://alepa.pa.gov.br/bancodeleis/cgibin/folioisa.dll/spld0001.nfo/query=*/doc/\{t1,4832\}?>. Acesso em: 03/11/2014.

RIBEIRO, T. F. O planejamento urbano como instrumento garantidor do direito à cidade. Revista de Direito da Cidade, v. 4, n. 1, p. 71-90, 2012.

SÁNCHEZ, F. A reinvenção das cidades para um mercado mundial. Chapecó: Argos, 2003. 
SANTOS, M. Espaço do Cidadão. 7. ed. São Paulo: Edusp, 2007.

SILVA, J. P. Cidadania e reconhecimento. In: AVRITZER, L.; DOMINGUES, J. (Org.). Teoria social e modernidade no Brasil. Belo Horizonte: UFMG, 2000.

TELLEZ, D. H. Q.; GANDARA, J. M. G. Aspectos de infraestrutura e serviços como indicadores de turistificação na Vila de Encantadas, Ilha do Mel (Brasil). Disponível em: <http://ojs.c3sl.ufpr.br/ojs/index.php/turismo/article/viewFile/22832/17717>. Acesso em: 02/11/2014.

TRINDADE JÚNIOR, S. C.; AMARAL, M. D. B. Reabilitação urbana na área central de Belém-Pará: concepções e tendências de políticas urbanas emergentes. Revista Paranaense de Desenvolvimento-RPD, n. 111, p. 73-103, 2016.

Recebido em: 11-05-2015.

Aprovado em: 11-06-2015. 